\title{
Rapid resolution of ST elevation and prediction of clinical outcome in patients undergoing thrombolysis with alteplase (recombinant tissue- type plasminogen activator): results of the Israeli Study of Early Intervention in Myocardial Infarction
}

Gabriel I Barbash, Arie Roth, Hanoch Hod, Hilton I Miller, Shemuel Rath, Yedahel Har-Zahav, Michaela Modan, Uri Seligsohn, Alex Battler, Elieser Kaplinsky, Babeth Rabinowitz, Shlomo Laniado

\begin{abstract}
Alteplase (recombinant tissue-type plasminogen activator (rt-PA)) was infused within four hours of onset of symptoms in 286 patients with acute myocardial infarction. Delayed coronary angiography was performed 72 hours after admission with coronary angioplasty if indicated. Electrocardiographic monitoring was continuous during the first hour of treatment. The sum of the ST segment elevations ( $\Sigma$ ST) was calculated on electrocardiograms recorded at entry and an hour later. ST elevations resolved rapidly within one hour of treatment in 189 patients and persisted in 97 patients. Rapid resolution of ST elevation correlated with angiographic coronary patency as determined by coronary angiography 72 hours after admission. The patients with rapid resolution of $\Sigma$ ST had significantly smaller infarcts and a better clinical outcome than the patients with persistent ST elevation. $\Sigma$ ST values at entry and one hour after treatment had no additional independent predictive value. Rapid resolution of ST elevations in patients undergoing thrombolysis with alteplase was associated with a significantly smaller release of creatine kinase, better preservation of left ventricular function, lower morbidity, and less short and long term mortality. Fapid resolution of $\Sigma$ ST elevation is an efficient indicator of clinical outcome in groups of patients with acute myocardial infarction undergoing thrombolysis with alteplase.
\end{abstract}

Thrombolytic treatment in acute myocardial infarction has been shown to be effective in preserving the ventricular ejection fraction ${ }^{12}$ and reducing short and long term mortality. ${ }^{34}$ Although 60 to $70 \%$ of treated patients can be successfully reperfused, ${ }^{5}$ thrombolytic treatment fails in a substantial proportion. These "non-responsive" patients have a significantly high mortality rate ${ }^{67}$ and may therefore be candidates for emergency angioplasty or coronary artery bypass surgery. We need early reliable indicators to distinguish between patients who will respond favourably to thrombolytic treatment and those who will not.

Coronary angiography immediately after treatment is the most accurate way to document coronary artery patency. However, only a few medical centres can provide timely angiographic evidence of reperfusion for each patient with myocardial infarction. Although resolution of pain and of ST segment elevation have been proposed as markers of myocardial reperfusion, ${ }^{8-10}$ it was recently argued that these markers are inadequate in predicting recanalisation of the infarct artery after thrombolytic treatment. ${ }^{112}$

The purpose of the Israeli Study of Early Intervention in Myocardial Infarction was to identify possible correlates of clinical outcome in patients with acute myocardial infarction after treatment with alteplase (recombinant tissue-type plasminogen activator (rt-PA)). Intravenous alteplase was given to 289 patients with acute myocardial infarction. The end points included evaluation of left ventricular function, morbidity, and mortality. This report describes the value of rapid resolution of ST segment elevations as an early clinical predictor of patient outcome.

\section{Patients and methods}

PATIENTS

The Sheba and Tel Aviv Medical Centres together have more than 2000 beds for acute cases. Both are regional hospitals serving a defined population of over one million. In October 1986 a collaborative study was started to examine the clinical outcome of patients with acute myocardial infarction undergoing early thrombolysis with alteplase and delayed coronary angiography. Patients were recruited via the emergency ward and by the mobile intensive care teams. The study protocol was approved by both institutional committees on human research and all participating patients gave their informed consent.

Tashomer, Ramat-Gan,

Accepted for publication 17 May 1990 
The entry criteria were age $<73$ years, severe chest pain for $>30$ minutes (but no longer than four hours), ST segment elevation of $0.1 \mathrm{mV}$ in at least two contiguous electrocardiographic leads, no left bundle branch block on the qualifying entry electrocardiogram, no congestive heart failure before admission, no history of cardiac surgery, diastolic blood pressure $<120 \mathrm{~mm} \mathrm{Hg}$, no history of terminal illness, no bleeding predisposition (that is, oral anticoagulant treatment, recent trauma, past bleeding history, or cerebrovascular accident during the past six months).

\section{THROMBOLYTIC REGIMEN}

A total dose of $120 \mathrm{mg}$ alteplase (G11035, supplied by Boehringer Ingelheim, West Germany) was given during a 6 hour infusion that consisted of a $10 \mathrm{mg}$ bolus followed by a continuous infusion of $50 \mathrm{mg}$ during the first hour, $20 \mathrm{mg}$ in the second hour, and $10 \mathrm{mg}$ during each of the following four hours.

Concomitantly, a bolus of 5000 IU of heparin was infused followed by 25000 IU per 24 hours. The dose was adjusted to keep the activated partial thromboplastin time 1.5 to 2 times the baseline. Heparin infusion was continued for at least five days except when patients underwent a successful coronary angioplasty (then heparin treatment was stopped after 24 hours); bled, or were referred for urgent (before discharge) coronary bypass surgery (then heparin was continued until operation). Aspirin $(250 \mathrm{mg}$ ) was given daily after the first 24 hours and continued during the follow up. Conventional antianginal and anticongestive treatment was used as needed. All patients were treated prophylactically with $2 \mathrm{~g}$ of intravenous lignocaine for the first 24 hours.

CORONARY ANGIOGRAPHY AND PERCUTANEOUS TRANSLUMINAL CORONARY ANGIOPLASTY

All patients underwent coronary angiography 72 hours after treatment began unless because of their clinical condition they needed earlier catheterisation. Five patients died before coronary angiography could be done, and in four patients coronary angiography was not performed because of unstable haemodynamic function. Patients with a reduction of $>50 \%$ in the luminal diameter of the infarct-related artery had angioplasty during the same session unless the infarct artery was a small branch and not important; when the lesion was regarded as unsuitable for angioplasty; or if they were referred for coronary bypass surgery because of three vessel coronary disease, or left main or left main equivalent disease. The clinical response to the thrombolytic treatment (ST resolution as specified below), was not a factor in the decision to perform mechanical revascularisation.

The patency of the coronary arteries was evaluated at each laboratory by a consensus reading of all angiograms by two angiographers who were unaware of the patient's clinical course except for the site of the infarction shown on the electrocardiogram. The severity of coronary artery disease was determined by visual assessment of the reduction in luminal diameter (percentage stenosis) and the Thrombolysis in Myocardial Infarction Trial (TIMI) ${ }^{13}$ gradings of perfusion of each coronary artery and its major branches. The success of angioplasty was evaluated visually and improvement was defined as a reduction in lumen stenosis $\geqslant 20 \%$ and a final lumen stenosis of $<60 \%$.

\section{LEFT VENTRICULAR FUNCTION}

During hospital stay each patient underwent three radionuclide studies to assess left ventricular function: the first as soon as possible after admission, but not later than 48 hours (mean (SD) time 22 (17) hours), the second immediately before the 72 hour coronary catheterisation, and the third at discharge.

Radionuclide studies were done with an Elscint Apex 415 digital gamma camera in the nuclear cardiology laboratories next to the coronary care unit. A multigated equilibrium blood scan was done in the anterior and $45^{\circ}$ left anterior oblique projection with red blood cells labelled in vivo with ${ }^{99} \mathrm{Tc}$ ( 20 to $25 \mathrm{mCi}$ ). The left ventricular ejection fraction was measured in the $45^{\circ}$ left anterior oblique projection. A left ventricular time activity curve correlated to background was used to calculate the global ejection fraction semiautomatically. All radionuclide examinations and the left ventricular ejection fraction were assessed by the same two experienced cardiologists who were unaware of the clinical course of the patients examined. For purpose of analysis, the left ventricular ejection fraction at discharge was considered to be zero for the four patients who died before discharge.

\section{PATIENT EVALUATION}

All patients stayed in the coronary care unit for at least 24 hours. Patients scored their level of pain from 1 to 10 with the pain level before treatment defined as 10 . Significant relief of pain was defined as a reduction of at least $50 \%$ within one hour after the start of alteplase infusion. Serial 12 lead electrocardiogram tracings were obtained every three hours during the first 24 hours and at least once daily thereafter until discharge. In addition, a 12 lead electrocardiogram was obtained every 15-30 minutes during the first two hours of treatment or until the ST segment elevation was resolved. Blood samples for creatine kinase were collected every three hours during the first 24 hours. The creatine kinase $M B$ isoenzyme fraction was calculated from the sample in which the creatine kinase concentration was highest. After discharge, patients had follow up clinic visits at 2,6 , and 12 months and once annually thereafter. Surviving patients completed a one year follow up.

\section{CLINICAL DEFINITIONS}

Infarction.-The diagnosis of myocardial infarction was based on the occurrence of ischaemic chest pain lasting $>30$ minutes and accompanied by ST segment elevation of at least $0.1 \mathrm{mV}$ in two contiguous electrocardiographic leads, followed by either an increase in the serum concentration of the creatine 
kinase $\mathrm{MB}$ fraction of $>5 \%$, or the appearance of new $Q$ waves not present on the initial electrocardiogram. Abnormal $Q$ waves were those lasting $\geqslant 0.03$, at least $4 \mathrm{~mm}$ deep, and $>25 \%$ of the height of the ensuing $R$ wave all in leads other than aVR or V1.

Rapid resolution of ST segment elevation.-As in earlier reports, ${ }^{1314}$ we calculated the sum of ST segment elevations ( $\Sigma$ ST) on the electrocardiograms recorded at admission and 1 hour after treatment. Electrocardiograms were evaluated within the first 24 hours after admission by two independent observers, one from the coronary care unit treating the patient and one observer who was not involved in the care of these patients. In cases of disagreement, a third opinion was sought. Resolution of ST segment elevation was defined as a decrease of at least $50 \%$ of the baseline $\Sigma$ ST elevation.

Patency.-A TIMI grade of 2 or 3 signified patency of the infarct related coronary artery. Occlusion of the infarct-related artery was defined as TIMI grade 0 or $1 .^{15}$

Clinical prognostic groups.-Patients were categorised as having a first infarction in the anterior or inferior wall or a history of infarction irrespective of the location of the current infarction.

\section{STATISTICAL ANALYSIS}

Group data are expressed as mean (SD) for continuous variables or as rates (percentage) for categorical variables. For continuous variables we used the Mann-Whitney rank sum test for univariate comparisons of differences between patients with and without rapid resolution of $\Sigma S T$ because the variance in some of the variables was unequal. For categorical variables, we used the $\chi^{2}$ or, when appropriate, Fisher's exact test for $2 \times 2$ tables. Logistic regression analysis (Biomedical Computer Programs, University of California, Berkley CA-BMDP program LR) was performed wth rates of each of the following six outcomes as the dependent variable: immediately abnormal $(<50 \%$ ejection fraction) left ventricular function, abnormal left ventricular function at discharge, congestive heart failure at discharge, $Q$ wave infarction, angiographic occlusion of the coronary artery, and mortality.

The effect of the following independent risk

Table 1 Baseline characteristics of patients with rapid ST elevation and without

\begin{tabular}{|c|c|c|c|}
\hline Characteristic & $\begin{array}{l}\text { Rapid reduction } \\
\text { of } S T \text { elevation } \\
n=189(100 \%)\end{array}$ & $\begin{array}{l}\text { Persistent elevation } \\
\text { of } S T \text { elevation } \\
n=97(100 \%)\end{array}$ & p Value \\
\hline $\begin{array}{l}\text { Male }\left({ }^{\circ}{ }_{0}\right) \\
\text { Age }(\text { mean }(\mathrm{SD})) \\
\text { Anterior infarction }\left({ }^{\circ}{ }_{0}\right) \\
\text { Inferior infarction }\left({ }^{\circ}{ }_{0}\right) \\
\text { Previous infarction }\left({ }^{\circ}{ }_{0}\right) \\
\text { Single vessel disease }\left({ }^{\circ}{ }^{\circ}{ }^{\circ}\right) \\
\text { Mean (SD) systolic BP } \\
\text { Mean (SD) time to treatment (min) }\end{array}$ & $\begin{array}{r}160 \cdot 0(84 \cdot 7) \\
56 \cdot 6(9 \cdot 5) \\
68 \cdot 0(36 \cdot 0) \\
97 \cdot 0(51 \cdot 3) \\
24 \cdot 0(12 \cdot 4) \\
87 \cdot 0(46 \cdot 0) \\
125 \cdot 7(22 \cdot 1) \\
123 \cdot 7(51 \cdot 2)\end{array}$ & $\left.\begin{array}{r}83 \cdot 0(83 \cdot 0) \\
58 \cdot 6(8 \cdot 9) \\
44 \cdot 0(45 \cdot 4) \\
28 \cdot 0(28 \cdot 9) \\
25 \cdot 0(25 \cdot 7) \\
41 \cdot 0(42 \cdot 3) \\
127 \cdot 2(28 \cdot 2) \\
112 \cdot 4(43 \cdot 6)\end{array}\right\}$ & $\begin{array}{l}0.97 \\
0.09 \\
0.05 \\
0.94 \\
0.94 \\
0.053+\end{array}$ \\
\hline
\end{tabular}

^Excluding five patients who died before coronary angiography was performed and two patients who did not have coronary angiography because their haemodynamic condition was unstable. BP, blood pressure.

†ANOVA test for unequal variances. variables related to $\Sigma$ ST change on the outcome variables was analysed: persistent ST elevation $(<50 \%$ reduction in $\Sigma$ ST) for at least one hour after treatment began, $\Sigma$ ST at admission, $\Sigma$ ST one hour after the start of treatment, and the ratio of the two $\Sigma$ ST values as continuous variables. Additional independent risk variables were: persistence of chest pain for at least one hour after the start of treatment, number of diseased coronary vessels, clinical prognostic group, age, sex, and smoking. The independent risk ratios (with $95 \%$ confidence intervals) associated with each of the independent variables were derived from the logistic coefficients.

\section{Results}

PATIENTS' BASELINE DATA

Two hundred and eighty six patients were eligible for thrombolytic treatment. Of these, 169 were admitted via the emergency ward and 117 patients were brought in by the mobile intensive care units. The mean (SD) time from onset of symptoms to treatment was $2 \cdot 0(0 \cdot 6)$ hours.

Table 1 shows the demographic and clinical characteristics of patients at entry. In 189 patients $(66.0 \%)$ we saw rapid resolution of ST segment elevation, whereas in 97 patients $(33.9 \%$ ) ST segment elevation persisted despite an hour of alteplase infusion. The two groups were generally comparable. In the group of patients with rapid resolution of ST elevation, however, anterior wall infarction was less common, previous infarction was more common, and the time from onset of symptoms to the start of treatment was longer (124 (51) $v$ 112 (44) min respectively, $\mathrm{p}=0.053$ ). In the patients with anterior wall infarction with rapid resolution of ST elevation and in those without, baseline $\Sigma$ ST elevation was 18.3(9.4) and $22.3(12.8)$ respectively ( $p=N S$ ). In those with inferior wall infarction, baseline $\Sigma$ ST elevation was $8.4(4.2)$ in those with rapid resolution of ST elevation and $10.5(6.8)$ in those without ( $\mathrm{p}=\mathrm{NS}$ ). The baseline $\Sigma \mathrm{ST}$ elevation in patients with previous infarction was similar in patients with rapid resolution of ST elevation and those without $(11.8(5.5) v$ $15 \cdot 3(9 \cdot 9), \mathrm{p}=\mathrm{NS}$ ).

In 10 patients the initial clinical picture of myocardial infarction was not confirmed by an increase in the activity of the $M B$ isoenzyme fraction of creatine kinase or the development of new $Q$ waves on their electrocardiograms. All 10 patients showed rapid resolution of ST elevation. We present the results for the total group, because exclusion of these patients from analysis did not affect the differences between the patients with rapid ST resolution and the patients with persistent ST elevation.

\section{PAIN RESOLUTION}

Pain resolved quickly in $153(85.9 \%)$ of 178 patients with rapid resolution of ST elevation and in only $21(22.3 \%)$ of 94 patients with persistent ST elevation (the change in pain was not recorded in 11 patients with rapid ST resolution and in three patients with persistent 
ST elevation) ( $p<0.0001)$. The outcome of the 25 patients with rapid resolution of ST elevation but no pain resolution resembled that in the 153 patients who had resolution of both pain and ST segment elevation. The 21 patients with abrupt pain relief but no ST resolution resembled the 73 patients with persistent pain and ST elevation (data not shown). Consequently, data are categorised by the presence or absence of rapid resolution of ST segment elevation, irrespective of pain resolution.

\section{MYOCARDIAL ENZYME KINETICS}

Rapid resolution of ST elevation was associated with significant limitation of infarct size as reflected by a smaller creatine kinase peak (fig 1) and total release of creatine kinase over the first 24 hours (sum of all samples measured as area under the curve) (table 2). Total 24 hour creatine kinase release was significantly lower in patients with rapid resolution of ST elevation in all prognostic clinical groups than in patients with persistent ST elevation (table 2).

\section{LEFT VENTRICULAR FUNCTION}

Patients with rapid ST resolution and those without differed markedly in the preservation of their left ventricular function. Both the proportion of patients whose left ventricular ejection fraction was normal immediately after admission ( $>50 \%$ ) and at discharge (fig 2) and the mean ejection fraction (table 3 ) were significant higher in the group with rapid resolution of ST elevation. This difference was more prominent in the patients with anterior wall infarction than in those with inferior wall infarction or old infarction. However, left ventricular function at admission and at discharge was better in patients with inferior wall infarc-

Figure 1 Peak serum concentration of creatine concentration of creatine
kinase during the first 24 hours in patients with rapid resolution of $S T$ elevation and without.

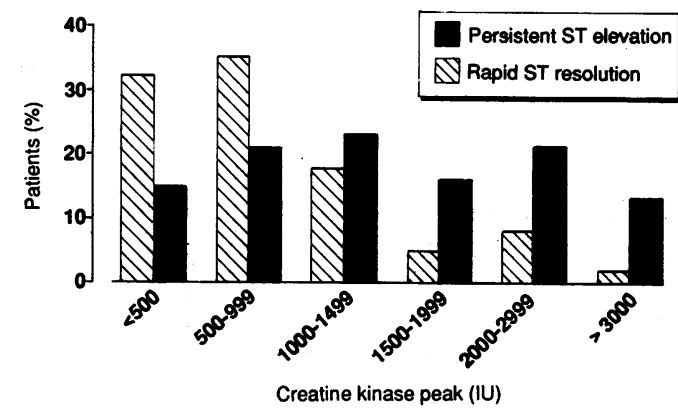

Table 2 Total release of creatine kinase in $24 \mathrm{~h}$ in patients with rapid reduction of ST segment elevation and without

\begin{tabular}{|c|c|c|c|c|c|}
\hline \multirow[b]{3}{*}{ Patient group } & \multicolumn{4}{|c|}{ Rapid reduction of ST elevation } & \multirow[b]{3}{*}{$p$ Value $e^{\star}$} \\
\hline & \multicolumn{2}{|l|}{$\overline{Y e s}$} & \multicolumn{2}{|c|}{ No } & \\
\hline & $n \dagger$ & $I U(S D)$ & $\overline{n+}$ & $I U(S D)$ & \\
\hline $\begin{array}{l}\text { Total } \\
\text { Anterior infarction } \\
\text { Inferior infarction } \\
\text { Previous infarction }\end{array}$ & $\begin{array}{r}173 \\
65 \\
88 \\
20\end{array}$ & $\begin{array}{l}5248(4265) \\
6014(4790) \\
4939(3973) \\
4118(3354)\end{array}$ & $\begin{array}{l}84 \\
37 \\
25 \\
22\end{array}$ & $\begin{array}{r}10553(7762) \\
13408(9441) \\
7691(4382) \\
9002(6062)\end{array}$ & $\begin{array}{r}<0.0001 \\
<0.0001 \\
0.0002 \\
0.0015\end{array}$ \\
\hline
\end{tabular}

*Mann-Whitney rank sum test. with persistent $S T$ elevation. In these 29 patients incomplete sampling prevented calculation of the total release of creatine kinase. tion than in the other two groups. The mean left ventricular ejection fraction determined by ventriculography during cardiac catheterisation on the third day after admission was also significantly higher in the patients with rapid ST resolution (59 (13) $v 49$ (13), $\mathrm{p}<0.0001$ ).

\section{CLINICAL OUTCOME}

The proportion of patients who underwent mechanical revascularisation procedures was similar in patients with rapid resolution of ST elevation and in those without. Thus of the 189 patients with rapid resolution of ST elevation, $124(65.6 \%)$ had angioplasty or bypass procedures, and $52(53.6 \%)$ of the 97 patients with persistent ST elevation underwent mechanical revascularisation.

Coronary angiography was performed 4.0 $(1 \cdot 7)$ and $4 \cdot 1(2 \cdot 1)$ days respectively after enrolment of the patients with rapid ST resolution and the patients with persistent ST elevation. Coronary angioplasty was performed $4 \cdot 7(1 \cdot 4)$ and $3.8(2.0)$ days respectively after enrolment in the patients with rapid ST resolution and the patients with persistent ST elevation ( $\mathrm{p}=$ NS). In both groups, about a quarter of the coronary interventions were performed within the first 72 hours. Coronary angioplasty was successful in $96 \%$ of the patients with rapid ST resolution and $94 \%$ of the patients with persistent ST elevation.

At discharge, patients with rapid resolution of ST elevation had a better outcome in terms of a significantly lower incidence of congestive heart failure (defined as requirement for digoxin or diuretics at discharge) and a higher incidence of non- $Q$ wave infarction (fig 2 and table 4). This difference was more pronounced in the patients with anterior infarctions.

\section{MORTALITY}

Thirteen patients $(4.5 \%)$ died within 60 days of infarction; eleven of these died in hospital $(3.8 \%)$. Patients with rapid resolution of ST elevation had a lower 60 day mortality (3/189 v $10 / 97, \mathrm{p}=0.0015)$. Of the 10 patients with persistent ST elevation, one patient with anterior wall infarction died of ventricular fibrillation 10 minutes after treatment began. In the remaining nine patients (six with anterior wall infarction and three with inferior infarction) cardiogenic shock developed, and in two patients a ruptured myocardium was eventually found. Two of the three patients who responded to the alteplase infusion with rapid resolution of ST elevation had an anterior wall infarction and the third had an inferior wall infarction. In all three patients acute reinfarction with cardiogenic shock developed-in two within hours of coronary angiography and angioplasty:

Five additional patients died between 2 and 24 months after infarction (mean follow up time of 24.3 (3.4) months). Three of these patients originally did not show ST segment resolution: two patients died two and three months later of reinfarction and cardiogenic shock and the third died three months later of anaphylactic shock (non-cardiac death). Two additional patients who initially responded 
Figure 2 Clinical outcome in patients with rapid resolution of $S T$ elevation and without. $L V E F$, left ventricular ejection fraction; $\mathrm{CHF}$, congestive heart failure.

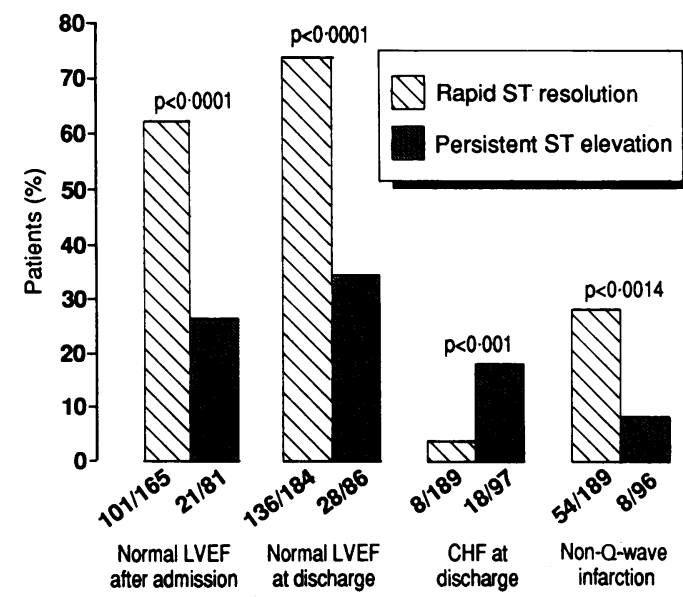

Table 3 Left ventricular ejection fraction in patients with rapid reduction of $S T$ segment elevation and without

\begin{tabular}{|c|c|c|c|c|c|}
\hline \multirow[b]{3}{*}{ Patient group } & \multicolumn{4}{|c|}{ Rapid reduction of $S T$ elevation } & \multirow[b]{3}{*}{ p Value ${ }^{\star}$} \\
\hline & \multicolumn{2}{|l|}{ Yes } & \multicolumn{2}{|l|}{ No } & \\
\hline & $n$ & $L V E F^{\star}(S D)$ & $n$ & $L V E F(S D)$ & \\
\hline $\begin{array}{l}\text { Total population: } \\
\text { Immediate LVEF } \\
\text { Discharge LVEF }\end{array}$ & $\begin{array}{l}165 \dagger \\
184 \dagger\end{array}$ & $\begin{array}{l}52(13) \\
55(12)\end{array}$ & $\begin{array}{l}81 \dagger \\
86 \dagger\end{array}$ & $\begin{array}{l}41(15) \\
44(14)\end{array}$ & $\begin{array}{l}<0.0001 \\
<0.0001\end{array}$ \\
\hline $\begin{array}{l}\text { Anterior wall infarction: } \\
\text { Immediate LVEF } \\
\text { Discharge LVEF }\end{array}$ & $\begin{array}{l}53 \\
66\end{array}$ & $\begin{array}{l}46(13) \\
53(14)\end{array}$ & $\begin{array}{l}37 \\
40\end{array}$ & $\begin{array}{l}33(11) \\
39(14)\end{array}$ & $\begin{array}{l}<0.0001 \\
<0.0001\end{array}$ \\
\hline $\begin{array}{l}\text { Inferior wall infarction: } \\
\text { Immediate LVEF } \\
\text { Discharge LVEF }\end{array}$ & $\begin{array}{l}91 \\
96\end{array}$ & $\begin{array}{l}57(10) \\
58(9)\end{array}$ & $\begin{array}{l}25 \\
26\end{array}$ & $\begin{array}{l}55(11) \\
53(12)\end{array}$ & $\begin{array}{l}0.44 \\
0.052\end{array}$ \\
\hline $\begin{array}{l}\text { Old infarction: } \\
\text { Immediate LVEF } \\
\text { Discharge LVEF }\end{array}$ & $\begin{array}{l}21 \\
22\end{array}$ & $\begin{array}{l}46(15) \\
49(16)\end{array}$ & $\begin{array}{l}19 \\
20\end{array}$ & $\begin{array}{l}38(12) \\
41(11)\end{array}$ & $\begin{array}{l}0.09 \\
0.09\end{array}$ \\
\hline
\end{tabular}

^Mann Whitney rank sum test.

†Excluding 40 immediate and 16 discharge radionuclide ventriculographies that were missing or were not suitable for interpretation. The discharge LVEF was nominally 0 in the 11 patients who died before discharge.

LVEF, left ventricular ejection fraction $(\%)$.

Table 4 Clinical outcome in patients with rapid reduction of ST elevation and without

\begin{tabular}{|c|c|c|c|}
\hline \multirow[b]{2}{*}{ Characteristic } & \multicolumn{2}{|c|}{ Rapid reduction of $S T$ segment elevation } & \multirow[b]{2}{*}{ p Value } \\
\hline & Yes $(\%)$ & No $(\%)$ & \\
\hline $\begin{array}{l}\text { Congestive heart failure } \\
\text { Total population } \\
\text { Anterior infarction } \\
\text { Inferior infarction } \\
\text { Previous infarction }\end{array}$ & $\begin{array}{ll}8 / 189 & (4 \cdot 2) \\
3 / 68 & (4 \cdot 4) \\
2 / 97 & (2 \cdot 0) \\
3 / 24 & (12 \cdot 5)\end{array}$ & $\begin{array}{r}18 / 97(18 \cdot 5) \\
8 / 44(16 \cdot 6) \\
2 / 28(7 \cdot 1) \\
8 / 25(32 \cdot 0)\end{array}$ & $\begin{array}{c}<0.001 \\
0.017 \\
0.21 \\
0.10\end{array}$ \\
\hline $\begin{array}{l}\text { Non-Q wave infarction } \\
\text { Total population } \\
\text { Anterior infarction } \\
\text { Inferior infarction } \\
\text { Previous infarction }\end{array}$ & $\begin{array}{cc}54 / 189 & (28 \cdot 6) \\
24 / 68 & (35 \cdot 3) \\
25 / 97 & (25 \cdot 8) \\
5 / 24 & (20 \cdot 8)\end{array}$ & $\begin{array}{l}8 / 96(8 \cdot 3) \\
1 / 43(2 \cdot 3) \\
5 / 28(17 \cdot 9) \\
2 / 25(8 \cdot 0)\end{array}$ & $\begin{array}{c}<0.001 \\
<0.0001 \\
0.54 \\
0.19\end{array}$ \\
\hline
\end{tabular}

^Excluding one patient who died within 10 minutes of the start of treatment and in whom $Q$ wave infarction did not develop.

Figure 3 Cumulative mortality ( $\%$ ) of patients with rapid resolution of ST elevation and without.

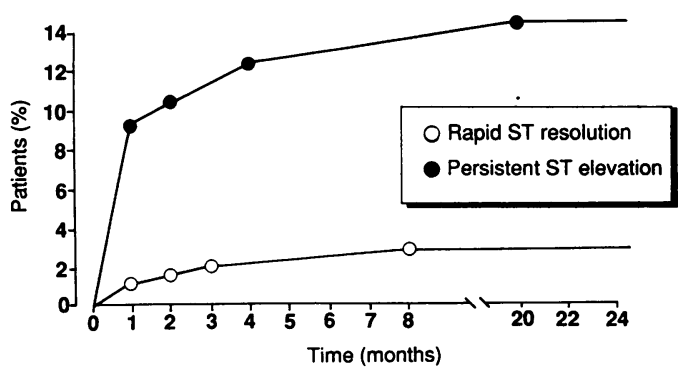

with rapid resolution of pain and ST segment elevation died: one in the third month of a ruptured septic aortic aneurysm and the other after eight months of hepatic malignancy. Thus overall mortality among the 97 patients with persistent ST elevation was higher than that in the 189 patients with rapid resolution of ST elevation $(13.4 \% v 2.6 \%, \mathrm{p}<0.0007)$ (fig 3 ).

CLINICAL MARKERS AND ANGIOGRAPHIC PATENCY Table 5 shows the correlation between the clinical response to thrombolytic treatment and patency of the infarct artery during coronary angiography after three days. At that time the patency rate of the infarct artery was higher in patients with rapid resolution of ST elevation $(86.6 \% v 76 \cdot 1 \%, \mathrm{p}=0.04)$.

In contrast with the strong association between a favourable clinical outcome and rapid resolution of ST segment elevation, the patency of the infarct artery at 72 hours was not associated with less creatine kinase release, preservation of left ventricular function, or lower morbidity after alteplase thrombolysis (table 6). Total mortality among angiographically assessed patients was lower in those with a patent infarct artery (eight of $231 v 5$ of $46, p=0.01)$. Even when the five deaths in patients who did not survive to angiography were included, persistent ST elevation was more common than occlusion of the infarct artery among patients who died (13 patients with persistent ST elevation compared with five patients with an occluded infarct artery among 18 who died).

\section{MULTIVARIATE ANALYSIS OF FACTORS AFFECTING} THE CLINICAL OUTCOME VARIABLES

Preliminary logistic regression analysis indicated that there were four measures related to the change in the ST elevation after treatment-that is, the continuous variables $\Sigma \mathrm{ST}$ at admission; $\Sigma$ ST one hour after treatment initiation; ratio of this value to the admission $\Sigma$ ST; or the categorical definition of $<50 \%$ reduction of $\Sigma$ ST from admission level (persistent ST elevation)-but only the last variable was strongly associated with all outcome variables and excluded the other three variables from the model. Consequently, the final analysis was done with persistent $\Sigma$ ST elevation alone.

The analysis evaluated the effect of each risk variable on each of the outcome variables after its association with other risk variables is taken

Table 5 Patency rate ( $\%$ ) of the infarct related artery at 72 hour coronary angiography and presence of rapid reduction of $S T$ elevation according to site of infarction

\begin{tabular}{llll}
\hline & \multicolumn{2}{l}{$\begin{array}{l}\text { Rapid reduction of } S T \\
\text { segment elevation }\end{array}$} & \\
\cline { 2 - 3 } & Yes & No & p Value \\
\hline Total population` & 86.6 & $76 \cdot 1$ & 0.043 \\
Anterior infarction & 93.9 & 80.5 & 0.035 \\
Inferior infarction & 81.4 & 85.7 & 0.41 \\
Previous infarction & 86.9 & 55.5 & $0.0224 \dagger$ \\
\hline
\end{tabular}

*Excluding five patients who died before coronary angiography and four patients in whom coronary angiography could not be performed because they were haemodynamically unstable.

†Fisher's exact test. 
Table 6 Clinical outcome in patients with a patent and an occluded infarct artery

\begin{tabular}{|c|c|c|c|c|c|}
\hline & \multicolumn{2}{|c|}{ Infarct artery patent } & \multicolumn{2}{|c|}{ Infarct artery occluded } & \multirow[b]{2}{*}{ p Value } \\
\hline & $n$ & $\operatorname{Units}(S D)$ & $n$ & $\operatorname{Units}(S D)$ & \\
\hline $\begin{array}{l}\text { Creatine kinase peak (IU) } \\
\text { Creatine kinase AUC } \\
\text { Immediate LVEF }(\%) \\
\text { Discharge LVEF }(\%)\end{array}$ & $\begin{array}{l}231 \\
212 \\
202 \\
225\end{array}$ & $\begin{array}{l}1260(1271) \\
6890(6294) \\
48(14) \\
52(14)\end{array}$ & $\begin{array}{l}46 \\
40 \\
42 \\
41\end{array}$ & $\begin{array}{l}1231(1068) \\
6816(4997) \\
48(15) \\
50(12)\end{array}$ & $\begin{array}{l}0.88 \\
0.94 \\
0.98 \\
0.34\end{array}$ \\
\hline $\begin{array}{l}\text { Congestive failure }(\%) \\
\text { Non-Q wave infarction }(\%) \\
\text { Total mortality }(\%)\end{array}$ & \multicolumn{2}{|c|}{$\begin{array}{l}13 / 230(5 \cdot 6) \\
54 / 231(23 \cdot 4) \\
8 / 231(3 \cdot 4)\end{array}$} & \multicolumn{2}{|l|}{$\begin{array}{l}5 / 45(11 \cdot 1) \\
9 / 46(19 \cdot 6) \\
5 / 46 \dagger(10 \cdot 8)\end{array}$} & $\begin{aligned} & 0.15 \\
0.71 & \\
< & 0.05 \ddagger\end{aligned}$ \\
\hline
\end{tabular}

*AUC, area under the curve representing the total release of creatine kinase during the first 24 hours after admission. tExcluding five patients who died before coronary angiography. †Fisher's exact test.

LVEF, left ventricular ejection fraction.

into account. For instance, the group with rapid resolution of ST segment elevation contained a greater proportion of patients with inferior wall infarction, which is itself associated with a more favourable outcome. Multivariate analysis gave a net risk ratio (relative risk of the group with rapid ST resolution and those without) for each outcome, which took into account the effect of the initial advantage. This analysis indicated that after accounting for all other risk variables, persistent ST elevation was associated with an independent, highly significant increased risk of all outcome variables, including infarct artery occlusion rate. It is noteworthy that abrupt resolution of pain had no independent predictive value for any of the outcome variables. Also, the value of the admission $\Sigma$ ST had no additional independent predictive value for clinical outcome.

Factors that had additional prognostic effect on left ventricular function included the clinical prognostic group, presence of three vessel coronary artery disease, age, and sex. Factors affecting congestive heart failure included clinical prognostic groups and age. In addition to rapid resolution of ST elevation, only the patient's prognostic group was predictive of mortality.

\section{Discussion}

The most conclusive evidence of reperfusion is the angiographic demonstration of recanalisation of an infarct related artery shown to be occluded during pre-treatment coronary angiography. However, to minimise the delay before treatment and to conserve costs most current thrombolytic protocols no longer include pre-treatment catheterisations..$^{16-18}$ Our medical centres, like many others, cannot routinely support immediate coronary angiography for all patients treated by thrombolysis. Moreover, recent results of the TIMI phase II, ${ }^{16}$ TAMI (Thrombolysis and Angioplasty in Myocardial Infarction), ${ }^{17}$ and the European Cooperative ${ }^{18}$ trials suggest that after successful thrombolysis, immediate coronary angiography and angioplasty may not be necessary. When post-thrombolytic coronary angiography is deferred for a few days, the patency rate reflects both the spontaneous and the (pharmacologically) induced coronary thrombolysis. Thus without early angiographic evidence of reperfusion, we are left with its clinical surrogates to identify patients with an unfavourable prognosis.

Our data indicate that the rapid resolution of ST segment elevation was significantly associated with a more favourable clinical outcome. In part, this more favourable outcome may have been related to the better baseline clinical characteristics in this group. However, even after the effect of this initial advantage was accounted for by multivariate analysis, this early clinical sign of reperfusion was significantly associated with a smaller infarct, as evidenced by a smaller release of creatine kinase, better preservation of left ventricular function, and significantly lower morbidity and mortality. Moreover, resolution of ST segment elevation was a better predictor of clinical outcome, including mortality, than was the patency rate determined by coronary angiography three days after admission (table 6). Multivariate analysis showed that the better outcome in the patients with rapid ST resolution was independent of their better baseline status (that is the lower rate of old or anterior wall infarctions or both as well as the initially lower $\Sigma$ ST). Our analysis indicates that the categorical variable of $50 \%$ resolution from the initial $\Sigma$ ST elevation to the one hour $\Sigma$ ST value was also superior to the change in $\Sigma \mathrm{ST}$ as a continuous variable.

These findings are consistent with those of the open-label phase of the TIMI Trial in which a decline in ST elevation from entry to two hours correlated with better left ventricular function in patients with acute myocardial infarction treated by thrombolysis. ${ }^{19} \mathrm{ST}$ segment elevation resolved more rapidly in patients treated with streptokinase than in the control group..$^{1320}$ Also, ST segment elevation decreased significantly within one and three hours after treatment in patients with confirmed angiographic reperfusion. ${ }^{142122}$

Despite this evidence, it was recently argued that clinical markers of reperfusion were inadequate predictors of early recanalisation of the infarct artery after thrombolytic treatment. ${ }^{11}$ In our patients, rapid resolution of ST elevation was associated with a higher patency rate in the infarct-related artery three days after treatment began. The difference in the patency rate between the two patient groups, though significant, was small $(86.7 v 76.9 \%)$. In view of this small difference in patency between the two groups, how could resolution of ST elevations predict the clinical outcome of our 
patients who were treated with thrombolysis? Moreover, how can the high patency rate in the group with persistent ST elevation be reconciled with their unfavourable outcome?

It could have been argued that angiography 72 hours after thrombolysis does not reflect the patency rate when alteplase infusion ended and that in patients with persistent ST elevation an earlier angiography would have detected lower patency rates. However, the patency rate $\left(76^{\circ}{ }_{0}\right.$ ) we saw (at 72 hours) in patients with persistent ST elevation was significantly higher than the $40^{\circ}$ o rate reported in patients with a three day old myocardial infarction who were not treated by thrombolysis. ${ }^{23}$ Thus coronary thrombolysis was successful in a substantial proportion of our patients with persistent ST elevation. But perhaps reperfusion was more effective in patients with rapid ST resolution than in those with persistent ST elevation. The effectiveness of the reperfusion may have been influenced by additional factors such as the existence of subtotal coronary occlusion or good collateral circulation, the rate and promptness of coronary artery recanalisation, and the residual stenosis in the infarct artery.

Thus rapid resolution of ST segment elevation may indicate a more effective reperfusion leading to a better clinical outcome. This possibility is supported by the fact that in the multivariate analysis rapid resolution of ST segment elevation was associated with a significantly favourable outcome with respect to all outcome variables after the effect of all baseline variables was accounted for. When ST segment elevation persisted despite one hour of alteplase thrombolysis, reperfusion was probably less effective even when angiographic patency was eventually seen. Because mechanical revascularisation procedures were performed to a similar extent in both groups, this factor could not have accounted for the better outcome of patients with rapid resolution of ST elevation.

Abrupt resolution of pain, though it was much more common among patients with rapid ST resolution, did not have any additional predictive power when combined with rapid resolution of ST elevation. However, as a sign of reperfusion, pain resolution is not very specific, partly because of the use of analgesics. Nevertheless, the outcome in patients with rapid resolution of $S T$ elevation but persistent ischaemic pain was similar to that in patients with resolution of both pain and ST elevation.

As a general strategy, immediate postthrombolytic coronary angiography has profound practical limitations. Round-theclock catheterisation laboratories are available in only a few medical centres. So after thrombolytic treatment in myocardial infarction there is a need for early, bedside, clinical measures to evaluate patients' response to treatment. Despite the strong association of rapid ST resolution with a more favourable outcome, it is limited in the identification of high risk patients who may need more vigorous treatment. This was shown by the finding that among patients with depressed left ventricular function, congestive heart failure, or $Q$ wave infarction, $>50 \%$ still had rapid resolution of ST elevation.
While rapid resolution of ST elevation may be a less effective indicator for the individual patient it is still a predictor of a better outcome and in patients treated by thrombolysis it can be used as a measure of the effectiveness of treatment in different subgroups.

We thank $\mathrm{L}$ Zalman, $\mathrm{R}$ Nash, and their teams for help in performing this study; $P$ Einstein and $Z$ Halevi for helping to performing this study; P Einstein and $Z$ Halevi for helping to analysis; and L Underhill for her help with preparing this paper.

1 Spann JF, Sherry S, Carabello A, et al. Coronary thrombolysis by intravenous streptokinase in acute myocardial infarction: acute and follow-up studies. $\mathrm{Am} \mathrm{J}$ Cardiol 1984;53:655-61.

2 Koren G, Weiss AT, Hasin Y, et al. Prevention of myocardial damage in acute myocardial ischemia by early treatment with intravenous streptokinase. $N$ Engl $\mathrm{J}$ Med 1985;313:1384-9.

3 Gruppo Italiano per lo Studio della Streptochinasi nell'Infarto Miocardico (GISSI). Effectiveness of intravenous thrombolytic treatment in acute myocardial infarction. thrombolytic treatment

4 Gruppo Italiano per lo Studio della Streptochinasi nell'Infarto Miocardico (GISSI). Long-term effects of intravenous thrombolysis in acute myocardial infarction: final ous thrombolysis in acute myocardial infarction:

5 Marder VJ, Sherry S. Thrombolytic therapy; current status. $N$ Engl J Med 1988;318:1512-20.

6 Kennedy JW, Ritchie JL, Davis KB, Stadius ML, Maynard $\mathrm{C}$, Fitz JK. The western Washington randomized trial of intracoronary streptokinase in acute myocardial infarction. A 12-month follow-up report. $N$ Engl J Med 1985;312:1073-8.

7 Topol EJ, Califf RM, Kereiakes DJ, George BS. Thrombolysis and Angioplasty in Myocardial Infarction (TAMI) trial. J Am Coll Cardiol 1987;10:65B-74B.

8 Ganz W, Geft I, Shah PK, et al. Intravenous streptokinase in evolving acute myocardial infarction. Am J Cardiol 1984;53:1209-16.

9 Rentrop P, Blanke H, Karsch KR, Kaiser H, Kostering H, Leitz K. Selective intracoronary thrombolysis in acute myocardial infarction and unstable angina pectoris. Circmyocardial infarction and
ulation 1981;63:307-17.

10 Mathey DG, Kuck KH, Tilsner VJ, Krebber HJ, Bleifeld W. Non surgical coronary artery recanalization in acute transmural $1981 ; 63: 489-97$

11 Kircher BJ, Topol EJ, O'Neill WW, Pitt B. Prediction of coronary artery recanalization after intravenous thrombolytic therapy. Am J Cardiol 1987;59:513-5.

12 Ross AM, TIMI investigators. Electrocardiographic and angiographic correlations in myocardial infarction patients treated with thrombolytic agents: a report from the NHLBI thrombolysis in myocardial infarction (TIMI) trial. J Am Coll Cardiol 1985;5:495A

13 Blanke H, Scherff F, Karsch KR, Levine RA, Smith H, Rentrop P. Electrocardiographic changes after streptokinase-induced recannalization in patients with acute left anterior descending artery obstruction. Circulation 1983;68:406-12.

14 Von Essen $R$, Schmidt $W$, Uebis $R$, et al Myocardial infarction and thrombolysis. Electrocardiographic short term and long term results using precordial mapping. $\mathrm{Br}$ term and long term result

15 The TIMI study group. The Thrombolysis in Myocardial Infarction (TIMI) trial. Phase I findings. $N$ Engl J Med 1985;312:932-6.

16 The TIMI Research Group. Immediate vs delayed catheterization and angioplasty following thrombolytic therapy for acute myocardial infarction. TIMI II $\mathrm{A}$ results. JAMA 1988;260:2849-58.

17 Topol EJ, Califf RM, George BS, et al. A randomized trial of immediate versus delayed elective angioplasty after intravenous tissue plasminogen activator in acute myocardial infarction. $N$ Engl J Med 1987;317:581-8.

18 Simoons ML, Arnold AE, Betriu A, et al. Thrombolysis with tissue plasminogen activator in acute myocardial infarction: no additional benefit from immediate perinfarction: no additional benefit from immediate per-

19 Bren GB, Wasserman AG, Sheehan FH, Forman S, Dodge HT, Ross AM, TIMI investigators. Electrocardiographic HT, Ross AM, TIMI investigators. Electrocardiographic evolution during acute myocardial infarction as a correlate
of left ventricular function outcome. Circulation 1985;72 of left ventricular funct

20 Anderson JL, Marshall HW, Bray BE, et al. A randomized trial of intracoronary streptokinase in the treatment of acute myocardial infarction. $N$ Engl $J$ Med 1983; 308:1312-8

21 Krucoff MW, Green CE, Satler LF, et al. Non invasive detection of coronary artery patency using continuous ST-segment monitoring. Am J Cardiol 1986;57:916-22.

22 Hogg KJ, Hornung RS, Howie CA, Hockings N, Dunn FG, Hillis WS. Electrocardiographic prediction of coronary artery patency after thrombolytic treatment in acute myocardial infarction: use of the ST segment as a noninvasive marker. Br Heart $J$ 1988;60:275-80.

23 De Feyter PJ, van Eenige MJ, van der Wall EE, et al. Effects of spontaneous and streptokinase-induced recanalization on left ventricular function after myocardial infarction. Circulation 1983;67:1039-44. 